\title{
Generalización BCG e inmunodeficiencia
}

\section{CASO CLINICO}

S.A.G. es una paciente de 1 año 8 meses de edad portadora de una inmunodeficiencia de tipo celular, que ha sufrido una serie de infecciones de diversa etiología y entre ellas la más grave, una generalización de la vacuna BCG.

La evolución clínica está resumida en 1a Tabla № 1. Cabe destacar la complicación local de la vacuna que se ulcera hasta alcanzar un diámetro de $3 \mathrm{~cm}$. y se acompaña de adenopatia axilar que supura y finalmente debe ser extirpada quirúrgicamente.

Las infecciones presentadas por esta niña eran causadas por diversos agentes:

1. Parásitos: Giardia Lambia en deposiciones y que recidiva pese al tratamiento.

2. Virus: Estomatitis herpética prolongada (de los 9 a 12 meses de edad).

Varicela de curso más prolongado, pero no severa.

3. Bacterias: Bronconeumonia a los 10 meses.

Infeccion urinaria por E. Coli (que también recidiva).

4. Hongos: Una de las infecciones más severas y de carácter crónico. Se inicia con algorra bucal y luego se extiende a zora gluteogenital. teiidos veribucales. dorso, cuello y cuero cabelludo. Se aislo Cándida

\footnotetext{
"Unidad de Inmunologfa Hospttal L. Calvo Mackenna.

-Instituto Bacteriologico de Chile.
}

\author{
Drs, Juan Quintana B.*, Roger Lamas S.", Sra. Li- \\ liana Rebolledo", Mitzi Reid"*. Ricardo \\ Sörensen ".*
}

\begin{abstract}
Albicans y resistió toda la terapéutica habitual.
\end{abstract}

5. Mycobacterias: A los 11 meses, a raíz de un cuadro séptico gravísimo, debió ser hospitalizada con diartea, anorexia rebelde, gran tendencia a deshidratación. recibiendo varias fleboclisis y transfusiones. Los exámenes demostraron bacilos BCG en mielocultivo y orina. En esa oportunidad se diagnostica diseminación BCG y se inicia tratamiento con drogas antituberculosas.

\section{REVISION DE LA LITERATURA}

Al revisar los casos de generalización de vacuna BCG (Tabla No: 2) destacan algunos hechos:

1. Escasa frecuencia: Se logró revisar sólo 21 casos.

2. Preponderancia en mutjeres sobre varones (2:1).

3. Curso fatal a corto plazo; 19 de 21 (90\%) faflecen rápidamente, pese a recibir todos ellos drogas antitubetculosas.

4. PPD negativo (excepto en 3 que se analizan más adelante), demostrando una alteración de la inmunidad celular y/o posiblemente afectados por la desnutrición que acompaña a todos estos enfermos.

5. Estudios inmunológicos: aue en el transcurso del tiempo se han ido perfeccionando y demuestran alteraciones en la mayoría de ellos de distinto tipo:

A.-Déficit mixtos de inmunidad celular y humoral: Linfopenia (menos de 1.000 linfo- 


$\begin{array}{ll}\text { Edad Manifestuciones clinicas } & \text { Tratamiento }\end{array}$

\begin{tabular}{|c|c|c|}
\hline RN (femenino) & Peso nac.: 2.700 & BCG (2 día) \\
\hline 1 mes & $\begin{array}{l}\text { Ulcera de } 1 \text { cm. en silio } \\
\text { inoculación BCG. }\end{array}$ & \\
\hline 3 meses & $\begin{array}{l}\text { Destete. Aplanamiento curva ponde. } \\
\text { ral. Resf ríos, bronquitis a repetición } \\
\text { y diarreas. }\end{array}$ & $\begin{array}{l}\text { Vitaminas } \\
\text { Antibíticos }\end{array}$ \\
\hline 8 meses & $\begin{array}{l}\text { Adenitis BCG supurada. } \\
\text { Giardia lambia. }\end{array}$ & $\begin{array}{l}\text { Local } \\
\text { Metronidazol }\end{array}$ \\
\hline 9 meses & $\begin{array}{l}\text { Estomatitis cherpética? prolongada } \\
\text { por } 3 \text { meses. }\end{array}$ & Local \\
\hline 10 meses & Bronconeumonia. & Penicilina $\times 10$ dias \\
\hline 11 meses & $\begin{array}{l}\text { ¿Sepsis? Hospitalización } x 48 \text { dias. } \\
\text { Infeceiơn urinaria por Klebsiela. } \\
\text { Varicela de curso prolongado. } \\
\text { Moniliasis bucal rebelde. } \\
\text { BCG en muelo y trocultivo. } \\
\text { Djarrea aguda con deshidratación. } \\
\text { Desnutrición II grado. }\end{array}$ & $\begin{array}{l}\text { Cloxacilina - Gentamicina } \\
\text { Furadantina } \\
\text { Nislatina } \\
\text { SM HIN PAS RMP diario } \\
\text { SM HIN ETA RMP diario } \\
\text { SM HIN bisem RMP' diario }\end{array}$ \\
\hline 1 año 2 meses & $\begin{array}{l}\text { Cicatriza adenitis BCG. } \\
\text { Infección urinaria por Klebsiela. } \\
\text { Moniliasis generalizada. }\end{array}$ & $\begin{array}{l}\text { SM HIN PAS bisem. } \\
\text { Furadantina } \\
\text { Nistatina Cancsten. }\end{array}$ \\
\hline 1 año 4 meses & $\begin{array}{l}\text { Reuparece adenitis BCG. } \\
\text { Moniliasis bucal intensa. }\end{array}$ & $\begin{array}{l}\text { Adenectomia } \\
\text { Anfotericina B - Fungizona }\end{array}$ \\
\hline & Urocultivo negativo para BCG. & HIN ETA bisemanal \\
\hline 1 ดก็น 7 meses & $\begin{array}{l}\text { Moniliasis de menot intensidad. } \\
\text { Desaparece moniliasis. } \\
\text { Buen estado general. }\end{array}$ & $\begin{array}{l}\text { Sulfato de Zin. } \\
\text { HIN ETA bisemanal }\end{array}$ \\
\hline 1 año 8 meses & $\begin{array}{l}\text { Reaparece moniliasis bucal. } \\
\text { Buen estado generat. } \\
\text { Mielo y urocultivo ncgativo para } \\
\text { BCG. }\end{array}$ & $\begin{array}{l}\text { Sulfato de Zinc } \\
\text { HIN ETA bisemanal }\end{array}$ \\
\hline
\end{tabular}

Peso nac.: 2,700
BCG (29 día) 
Tabla N: 2

DISEMINACION BCG EN NIÑOS DE TERMINO VACUNADOS EN PERIODO DE RN Y TRATADOS CON DROGAS ANTITUBERCULOSAS

(21 CASOS)

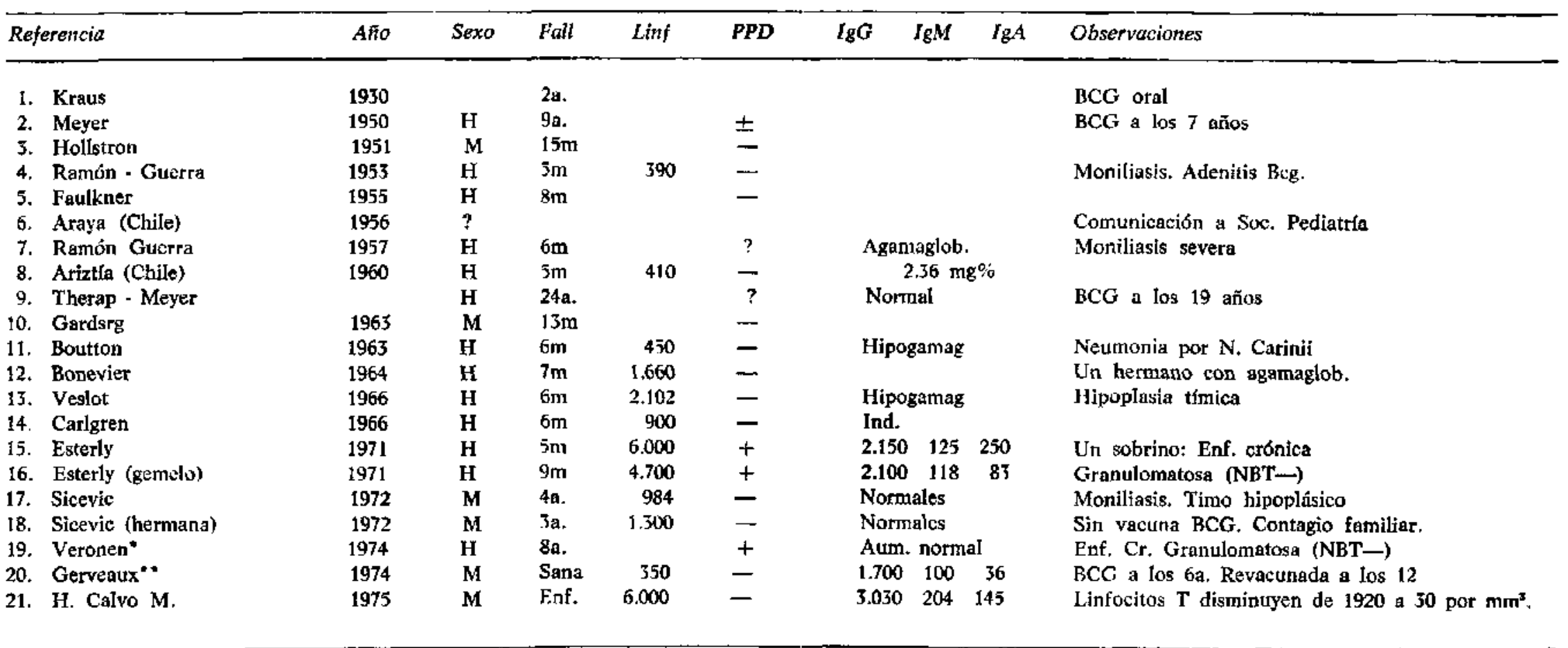

- Prestumible diseminación BCG, pero no se demostró el bacilo bacteriológicamente.

* Recibio corticoides. Mejora clinicamente. Se normaliza cifra linfocitos y test cutáneos. 
citos por $\mathrm{mm}^{3}$ ) asociado a hipo o agammaglobulinemia. Algunos de estos casos tienen cifra normal de linfocitos, pero como veremos un solo recuento y más aún sin diferenciar linfocitos T y B no descarta un déficit celular.

B.-Déficit de inmunidad celular: que corresponden a las últimas publicaciones de 1971 adelante. Estos enfermos presentan cifras normales de inmunoglobulinas y alteraciones inmunitarias que permite distinguir 3 grupos:

I.-Linfopenia: Manifiesta en las dos hermanas presentadas por Sicevic y que además tienen moniliasis asociada. La menor de ellas no recibió la vacuna $\mathrm{BCG}$, sino que adquiere la enfermedad al contagiarse con su hermana. En la autopsia se aisló el mismo bacilo BCG en ambas.

También hay linfopenia en la enferma presentada por Gerbeaux (13) en Francia, que recibe la vacuna BCG a los 6 años, a los 12 es revacunada y 3 meses más tarde presenta diseminación BCG en ganglios axilares, hígado y médula. Se trató con drogas antituberculosas y corticoides, mejorando clínicamente con normalización del rectrento de linfocitos y test cutáneos (PPD, DNCB, y Antígeno Monilia). Es la única viva y sana de la serie (aquí tambiến se observa un déficit parcial de $\operatorname{IgA}: 36 \mathrm{mg} \%$ ).

II.-Enfermedad Crónica Granulomatosa: Estos enfermos tienen exámenes aparentemente normales, incluso PPD positivo; sus polimorfonucleares y macrófagos son capaces de fagocitat $\odot$ ingerir bacterias, pero una vez dentro de la célula no son capaces de destruirla. En ellos el Test del Nitrobluetetrazolio (NBT) es negativo, demostrando una alteración de la capacidad metabólica intracelular. El enfermo presentado por Veronen (14) tenía esta enfermedad y probablemente los dos gemelos presentados por Esterly, (6) a quienes no se les hizo el NBT, pero que posterior a ellos fallece un sobrino con E. Cr. Granulomatosa y estudios posteriores demostraron que tanto la madre como la hermana de ambos tenían una menor actividad metabólica intracelular.

En álimo lugar tenemos a nuestra pacien- te, que está analizada más in extenso en Tabla No 3 y que difiere de los dos grupos anteriores. En este caso vemos que la inmunidad humoral está completamente normal (cifras repetidamente normales de: Inmunoglobulinas sérica y secretora, de $\mathrm{C}_{3} \mathrm{y}$ de complemento hemolítico. Igualmente normales son las cifras de linfocitos B). La alteración reside en la inmunidad celular demostrada por la negatividad de los test cutáneos $\mathrm{y}$ aparentemente debido a alteración funcional de linfocitos $T$, ya que pese a todos los exámenes destinados a precisar a qué nivel fallaba la respuesta inmune, nos encontrábamos siempre con cifras prácticamente normales, a excepción de una determinación de linfocitos $\mathrm{T}$ al año 6 meses en que sólo había 30 linfocitos $\mathrm{T}$ por $\mathrm{mm}^{3}$, pero que más tarde se normalizaron. coincidiendo con la adición de Sulfato de Zinc.

El estudio de inmunidad celular actual nos muestra: Linfocitos periféricos. Linfocitos $\mathrm{T}$ y $B$ en cantidad y proporciones normales. Estos linfocitos. al ser estimulados con PHA en cultivo de tejido, son capaces de multiplicarse en forma normal. La estructura ganglionar está conservada. EI NBT es positivo y los estudios de fagocitosis son normales para levaduras y monilias, no así para BCG, en que el índice fagocítico es aparentemente bajo, ya que los controles normales efectuados en el Instituto Bacteriolbgico son siempre superiores a 1.

Ante el pronóstico casi obligadamente fatal, como se puede desprender de la revisión literaria, y alentados por los excelentes resultados obtenidos al tratar con sulfato de zinc a un paciente con Acrodermatitis enteropática, (15) nos decidimos a emplear este medicamento en nuestra paciente.

El niño con Acrodermatitis enteropática, cuntrolado en conjunto con los Departamentos de Gastroenterología y Dermatología, y que ha sido motivo de una publicación", tiene en

*Guiraldes, E.; Sörensen, R.; Gutiérrez, C.; Coiré, P., y Gonzallez B.: Zinc sulphate for Acrodermatitis Enteropathica. Lancet. 2; 710, 1975. 
Tabla N: 3

BECEGEITIS GENERALIZADA

S. A. G. (Desnutrición, diarrea crónica, moniliasis). Grupo AB, Rh +; Típificación HLA: xlx2/ 2W10Y1

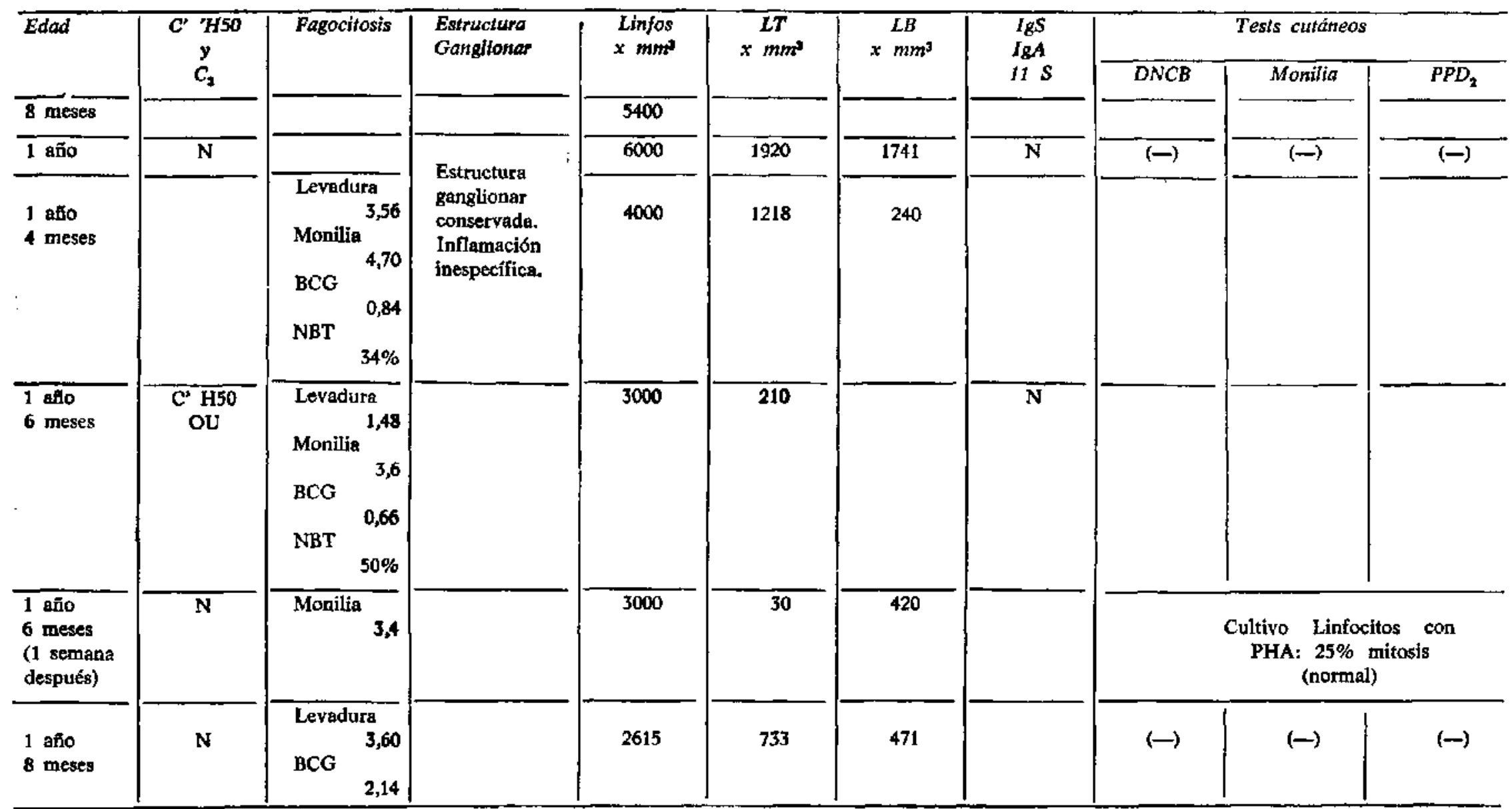


común con nuestra enferma los siguientes hechos: déficit de inmunidad celular manifestado por tests cutáneos negativos (y que se normalizaron después de terapia con Zinc); diarrea crónica, moniliasis generalizada resistente a tratamiento habitual y desnutrición.

Por estas razones, al año 7 meses de edad nos decidimos usar Sulfato de Zinc, $50 \mathrm{mg}$. dos veces al día. Con esto se observó una franca mejoría del estado general, reducción de esplenonegalia de 4 a $2 \mathrm{cms}$. y una completa desaparición de los hongos, que sin embargo, reaparecieron a los 15 días en boca y cuello. Los exámenes de laboratorio muestran un aumento de Linfocitos $T$ a cifras normales $y$ un notable aumento del índice fagocítico para BCG desde 0.66 a 2.14. Los tests cutáneos persisten negativos. El Uro $\mathbf{y}$ Mielocultivos para BCG son negativos.

Actualmente, en nuestra paciente se ha logrado erradicar los bacilos BCG de médula y orina, pero persisten su desnutrición y la moniliasis crónica, por la cual se mantiene en control médico.

\section{SUMMARY}

A girl of 1 y 8 months of age with a diseminated BCGitis is presented. Her birth weight was $2.700 \mathrm{~g}$. she received $B C G$ vaccination at the second day. Her development was umeventful until the age of 3 month, when breastfeeding was stopped. Since then she presented failure to thrive and reposted infections of various types: virals: prolonged stomatitis, parasitic: recurrent giardia lambia, bacterial; broncopneumonia and urinary infecticn, fungal: persistent. Candida Albicans skin and mucosa, and at age of 11 month, mycom bacteria in bone marrows and urine. This mycobacteria was identified later as being the same BCG strain.
Despite having a normal number of $\mathbf{T}$ Linphocytes and a normal response to PHA, the immunologic evaluation has shwon an incapacity to give normal skin reaction to candida, PPD and DNCB. The capacity to ingest dead BCG was persistently disminshed, but phagocytosis of yeast particles and candida was within normal values. Linphnode structure was normal.

After treatment with Isoniacida and ethanbutol BCG has desasappeared from bone narrows and urine (1 year and 7 month) but there is a persistent moniliasis of periorificial skin and mouth and failure to thrive. After initiating the administration of Zinc sulfate, her general condition and the ingestion of BCG improved, but skin test remains negative and monilis is still present in the mouth after 2 month of treatment.

\section{REFERENCIAS}

1. Aristia, A.: Rev, Chil. Ped. 31: 80, 1960.

2. Blatiner. et al.: J. Pediatrics, 65: 311, 1964.

3. Bonevier et al.: Acta Paediat. 53: 55, 1964.

4. Boutton J., et al.: Brit. Med. J. 1: 1512, 1963.

5. Carlgren, L.E. et al.: Acta Paed. Scand, 55: $636,1966$.

6. Esterly, J.R. et al.: Pediatrics. 48: 141, 1971.

7. Falkner, S. et al.: Actu Paed. 44: 219, 1955.

8. Gardborg, et al.: Acta Paed, 52: 293, 1963.

9. Ramón-Guerra, Au. et al.: Arch. Ped. de Uruguay. 29: 605, 1958.

10. Ramón-Guerra, Au, et al.: Rev. Chil. de Ped. 35: 605, 1964.

11. Sicevic, et al.: Acta Ped. Scand. 61: 178, 1972.

12. Vesiot, J, ef at:: Arch. Franc. Pediatrie. 23; $1113,1966$.

13. Gerbeaux, $J$. et al.: Arch. Franc. Ped. 31: 463, 1974.

14. Verronen, P. et al.: Acta Paed. Scand. 63: 627, 1974.

15. Guiraldes, E., Sörensen, R.: Lancet, 1975, en prensa. 